\title{
The Mind-mapping Approach (MMA): A Culture and Language "Free" Technique
}

\author{
Caroline M. Leaf \\ Isobel C. Uys \\ Brenda Louw \\ Department of Speech Pathology and Audiology \\ University of Pretoria
}

ABSTRACT

Although the roots of the Mind-Mapping approach (MMA) reach back into the depths of psychology, it is our growing understanding of the human brain, how it functions, what affects it, how we can assist it - which has become the real foundation for the model discussed in this paper. By finding ways of creating environments that are brain compatible - or rather-brain enhancing, we can begin to serve the whole person in all his dimensions. In this paper the need for language and culture "free" therapeutic technigues will be discussed. Reference is made to the author's research where the MMA was used very successfully with a closed head injured (CHI) client in order to demonstrate the effectiveness of the technique. The problem of CHI is also discussed. In addition, a brief theoretical review of the brain as it pertains to the concept of the MMA is offered. In the conclusion, it is suggested that global techniques such as the MMA, which are based on fundamental and universal principles, are the route to finding language and culture "free" techniques.

\section{OPSOMMING}

Alhoewel die oorsprong van die Breinkaartbenadering tot die grondbeginsels van die sielkunde teruggevoer kan word, is dit ons toenemende begrip van die menslike brein, die funksionering daarvan, waardeur dit beinvloed word en hoe breinfunksionering ondersteun kan word, wat die werklike grondslag uitmaak van die model wat in hierdie artikel bespreek word. Deur wysés te vind vir die daarstelling van omgewings wat breinfunksionering versterk, $k a n$ ' $n$ vertrekpunt gevind word vanwaar ons die kliënt as geheel in al sy dimensies kan benader.

Die behoefte aan "kultuururye" terapeutiese tegnieke word bespreek. Daar word verwys na die outeur se navorsing Die behoefte aan kultuururye terapeutiese geslote hoofbeserings word ook bespreek. Daarbenewens word 'n kort teoretiese oorsig van die brein, met betrekking tot die konsep van die Breinkaartbenadering tot intervensie, verskaf.

Ten slotte word daar voorgestel dat globale tegnieke soos die Breinkaartbenadering, wat gebaseer is op fundamentele en universele beginsels, die weg is waarvolgens "kultuurvrye" tegnieke gevind sal word.

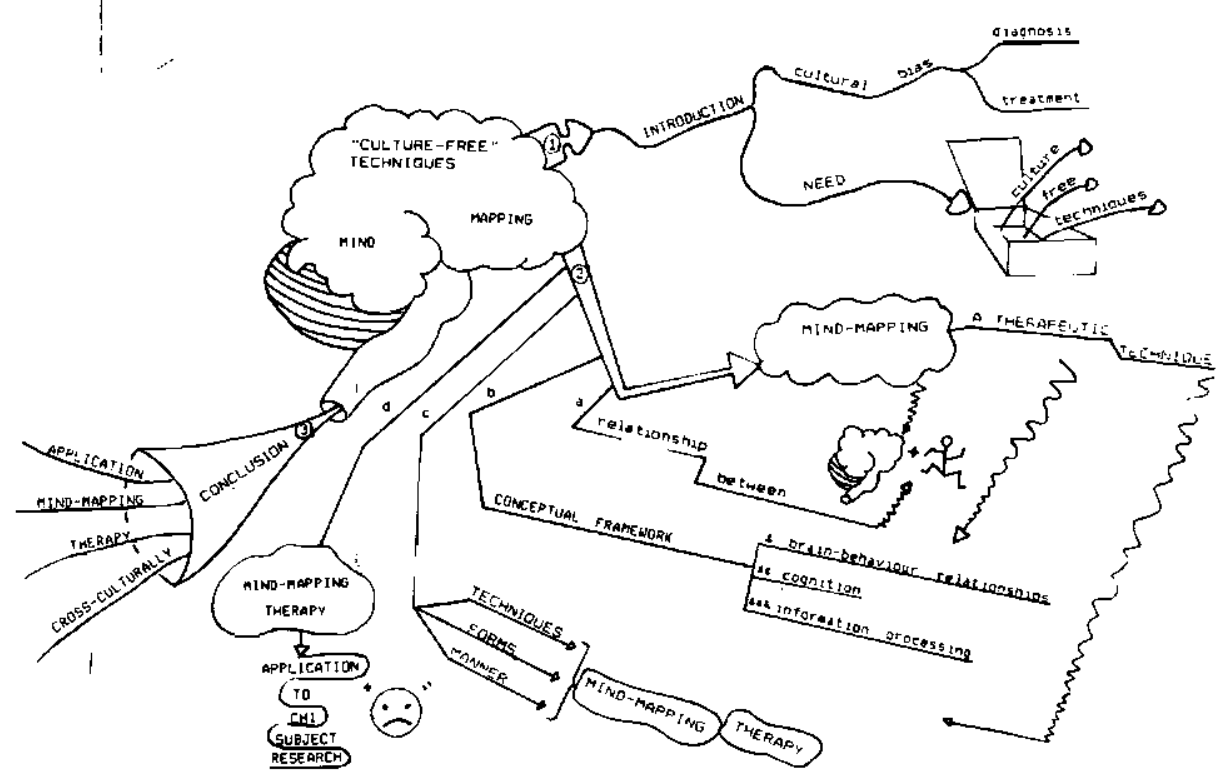

Die Suid-Afrikaanse Tydskrif vir Kommunikasieafwykings, Vol. 40, 1993 


\section{INTRODUCTION}

Speech-language and hearing therapy can be defined as "the delivery of services to (all) individuals with speechlanguage-hearing disorders, aimed at the amelioration of communication difficulties stemming from such disorders" (Uys \& Hay, 1985). Therefore, the provision of quality services to all groups and individuals is the goal of speech and language therapists worldwide. However, socio-economic, sociopolitical and demographic shifts over time have intensified "existing inequities in service delivery to specific groups" (ASHA, 1991:5).

In fact a great deal of disparity in service delivery exists in the profession (ASHA, 1991). Taylor (1986, p 3), attributes this disparity to two factors viz: Speech Therapists have a poor perception of the distinction "between a legitimate linguistic difference and a speech and language disorder". Secondly all communication norms are based on a middle-class Euro-American model (Taylor, 1986). Clearly, there is a need for greater understanding of dialect and language differences and for a clinical perspective that appropriately addresses these differences.

In South Africa it is extremely difficult to meet the needs of all individuals and to fulfil these goals as speech therapists are faced with two unique problems, namely:

- the therapist-patient ratio which is approximately 1 : 6000 annually;

- and the widely spread, multicultural, multilingual society (Uys \& Hay, 1985).

Therefore, in order to be effective, a therapist needs to learn a minimum of 30 languages and as many cultures (Uys \& Hay, 1985). Based on this argument, a therapist is not able to give effective accountable therapy cross-culturally. Hence, the need arises for culture and language free techniques that deal with this problem.

In this article, the Mind-Mapping Approach (MMA) developed by Leaf (1990) for Closed Head Injured (CHI) patients, will be discussed as a possible language and culture "free" technique for the multilingual and multicultural population group specifically of South Africa. The authors view language and culture as interdependent concepts, thus the language used is a reflection of the culture. The MMA is a Metacognitive technique and therefore the linguistic elements are not worked on directly. Thus, language is used as a tool in the MMA, as the MMA is a metacognitive technique (Leaf, 1990). If linguistic delays are presented by the client, these can be treated within the framework of the MMA.

\section{MIND-MAPPING : A THERAPEUTIC TECHNIQUE FOR CHI.}

$\mathrm{CHI}$ presents speech and language therapists with a unique diagnostic, prognostic and treatment challenge as a result of the widespread diffuse damage experienced by these patients, as well as the tendency to a lengthy recovery (Hagen, 1984). The general lack of understanding of the sequelae of CHI has inhibited the development of assessment tools, and few treatment guidelines have been proposed in literature. Thus there is a need for clinicians working with head injured patients to be able to identify and develop treatment regimes, that have functional goals involving behaviours that will make a difference in the way each person functions in his or her cultural environment (Adamovich, 1986). Due to the need for the development of accountable therapy techniques that deal with the complex problems of CHI, the strategy of Mind-Mapping therapy was developed and tested on a $\mathrm{CHI}$ subject (Leaf, 1990). As this research yielded exciting results, the technique will be elucidated in order to demonstrate the flexibility and effectiveness of this approach. It also provides a theoretical underpinning for the proposed concept of the MMA as a culture and language "free" technique.

The Mind-Mapping Approach (MMA) can be defined as a technique that organises and taps information in the brain by stimulating a synergistic effect between both hemispheres (Leaf, 1990). It is a way of structuring information that assists in the learning of new information (Leaf, 1990). As it is a psychoneurogenic technique based on the complex functioning of the brain, a brief theoretical review on the functioning of the brain as it pertains to the concept of the MMA is necessary.

The relationship between the functioning of the brain and the Mind-Mapping Approach (MMA).

It is an often quoted statistic that humans use only $10 \%$ of their potential brain power. However, the more researchers have learnt in the last 10 years, the less likely they are to attempt to quantify brain potential. The only apparent consistent conclusion is that the proportion of our potential brain power that is used is probably nearer $0.1 \%$ than $10 \%$ (Russell, 1986). In order to more fully utilize the brain's capacity one needs to consider each of the elements that comprise the way the brain functions. Once one begins to understand how the brain operates the way is opened to tap that vast unused potential. In this regard Sperry (1982), the pioneer of the first 'split-brain' experiments, that is cerebral localization studies on the functions of the two hemispheres, indicates that the integration of the left (more analytical) hemisphere and right (more creative) hemisphere, leads to enhanced functioning whilst thinking and learning.

The general opinion in the available literature is that the two hemispheres process information differently (dual brain theory). The intensity of the involvement of each depends upon the specific task (Sperry, 1982). For example, the hemispheres do not recall in sentences but in key concepts and images (Ornstein, 1975). Of the words heard, spoken or seen, only $1 \%$ to $10 \%$ are essential key words (Buzan, 1991). Every word is multi-ordinate, i.e. it hás a large number of links to other words (Buzan, 1991). In addition to this multi-ordinate nature of words, each brain is unique in the way it perceives images and is by nature both creative and organising (Zaidel, 1985). Finally, because recall is in images and words as opposed to sentences, thought processes are multi-dimensional and nonlinear (Buzan, 1991).

Ornstein indicates that by cultivating both hemispheres, the brain returns to a natural holistic way of functioning which in turn unlocks potential. Thus, stimulating a synergy between the two hemispheres is critical to effective accelerated learning. Hagin (in Van Kraayenberg, 1992), has pioneered research using techniques that stimulate brain hemisphere synergy on severely learning disabled children with remarkable success. Some of the tech- 
niques he has researched are ambidextrous writing and numerical techniques.

An additional example of this important research is research in the field of cerebral functioning, that has been conducted over the last $15-20$ years, namely the attempt to ascertain the biological processes involved in learning and memory (Rosenzweig \& Bennet, 1976). It is well documented that the brain is adaptable and that the brain appears to compensate for the damaged nerve fibres by:

- rerouting to alternative areas,

- the development of innate potentials in other areas of the brain, and

- gradual recovery from shock caused by injury (Luria, 1982).

A fact that has also emerged from this research - and that is very useful in terms of an evolving philosophy of remediation - is that these experiments have seemingly confirmed the susceptibility of the brain to actual physical and clinical changes resulting from training or enrichment of the environment (Rosenzweig \& Bennet, 1976). The possibility therefore exists that, under the right conditions, neurons may regenerate themselves, and be capable of growing new fibres indicating that they do have the genetic potential for reproduction. It has not yet been ascertained whether or not such a regeneration can occur in a normal nervous system, but the brain appears to make the maximum use of the possibilities open to it, and one of the most likely places to find such changes in nerve cell tissues would be in damaged tissue (Russell, 1986).

Rosenzweig and Bennet (1976) indicate that much of the research done in this area will undoubtedly lead to applications such as the alleviation of learning disability caused by neural malfunctions in perception, the prevention of senile decline in memory and learning, and better means of packaging information to aid learning and retrieval. This is the principle on which Mind-Mapping therapy (Leaf, 1990) is based.

Of particular interest to the above concepts is the research by Scott (1976), concerning neuron regeneration. Scott (1976) found that neurons can be induced to reproduce themselves if placed in a medium enriched in potassium ions - which are very important to axonal electrical conduction - this is called the K-mitotic effect. Scott (1976) argued that human adult neurons have the genetic potential to reproduce themselves. Unfortunately, however, the intriguing question is still left open as to why these neurons cannot exploit this reaction so as to produce true regeneration. Scott's findings, do however, make some inroads into the traditional idea that the neurons of the central nervous system are incapable of regeneration.

In evaluating the results of applying the Mind-Mapping strategy to a CHI patient (Leaf, 1990), spontaneous recovery cannot be overlooked as it is a controversial issue in terms of its interaction with treatment. It is estimated, that spontaneous recovery in a $\mathrm{CHI}$ subject extends up to 18 months post-accident (Adamovich, 1986). An additional complicating factor is that uncertainty exists about how treatment interacts with spontaneous recovery (Adamovich, 1986).

Based on the foregoing discussion on brain functioning, it is possible that Mind-Mapping therapy encourages spontaneous recovery to extend beyond the spontaneous capacity of the brain for physiological and structural change. Therefore, the MMA is a neuropsychological metacognitive-communication intervention technique that attempts to utilise to the fullest possible extent, the functional plasticity of neural tissue (Leaf, 1990). The concept is based on the idea that if the brain is given suitable and varied stimulation, it will continue developing and growing through life (Rosenzweig \& Bennet, 1976).

It is hypothesized that when Mind-Mapping therapy is initiated, Luria's (1982), process of intersystematic and intrasystematic reorganisation occurs. As the environment becomes enriched and progressively more organised as a result of this stimulation, new unused areas (previously not stimulated) take over function. As a result of this, an increase in potassium and sodium at the synapses probably occurs. These are important neurochemicals that can encourage collateral sprouting and regeneration of damaged neurons (Scott, 1976; Russell, 1986). The latter point has only been proved in the Central Nervous System (CNS) of animals (Scott, 1976) and, as most of our neuropsychological knowledge is based on application of animal research to humans, the above is a plausible deduction (Leaf, 1990).

Therefore, it is hypothesized that humans have a preset template of cognitive functioning that is moulded by the environment and mediators (significant people in the environment). In the brain's functional systems, however, there are other stores, i.e. potential connections that if stimulated, can carry out the cognitive activity lost or disrupted. The rationale for this is the unlimited potential of the brain and our underuse of it, that is we limit our brain by only using certain functional systems, whilst others lie dormant. If disruption due to brain damage occurs, the brain tries to restore equilibrium via compensatory strategies, for example, the patient elaborates, circumlocutes and perseverates (Penn and Cleary, 1988). In the MMA, the therapist acts as a mediator, and through a process of stimulating both the right and left hemispheres, the patient is assisted in searching the subconscious, unused stores to unlock this dormant potential and/or stimulate the regeneration of neurons (known as the K-mitotic effect). Ylvisaker and Szekeres (1986) also feel that increased spontaneous recovery can be effected by providing an enriched environment.

According to Leaf (1990), this concept advocates a plasticity of the brain with a reorganisation emphasis, as opposed to plasticity of the brain with a change in localisation of function emphasis. Therefore, with the MMA it is advocated that a new area of the brain is stimulated to learn to perform the function and, in doing this, the possibility that an enriched environment enabling regeneration and therefore restoration of the damaged functional system occurs.

This new concept stimulating brain hemisphere synergy, implies learning as opposed to equipotentiality and substitution, which implies a pre-existing spread of any function over the area - this underestimates the potential of the brain (Powell, 1981). There are many uncharted areas in the brain, and we are only beginning to understand our abilities. For instance Anokhin (1985 in Russell, 1986) calculated that the brain is capable of making 1 followed by 10 million kilometres of typewritten 0 's of connections. Furthermore, he estimated that an area the size of a pea in the human brain could control the entire world's telephone network system. 


\section{Development of a conceptual framework as a rationale for developing the Mind-Mapping approach (MMA).}

The concepts of brain-behaviour relationships, cognition and information processing will be discussed in the following section, in order to elucidate the rationale of the Mind-Mapping approach (MMA) developed by the first author and used with a CHI subject (Leaf, 1990).

\section{Brain-behaviour relationships}

Luria's emphasis on understanding brain functions as interlocking functional subsystems has been a particularly important concept in the Mind-Mapping approach (Luria, 1982). While the diffuse and complex neuropsychological deficits that seem to accompany severe traumatic head injury make it difficult to apply Lurian assessment and remediation techniques, his general approach to appreciating the interconnectedness of many cognitive functions has been vital.

According to Luria (1982), the destruction of cortical tissue has an effect on the entire functional system to which it contributes because a link within the functional chain has been weakened or damaged. Two situations can occur, namely:- intersystematic - incorporating a new link from a different functional system ; intrasystematic - vertical shift within a functional system (Luria, 1982).

In the MMA it is hypothesized that, initially both intersystemic and intrasystemic reorganisation occur (Leaf, 1990). This could lead to the areas around the neurons becoming enriched because of this stimulation resulting in two possible occurrences, namely:- new unused areas take over function; and collateral sprouting and regeneration (Scott, 1976) occur resulting in restoration of function. Restoration to original and possibly higher levels of original functioning may occur.

To conclude: by applying Lurian concepts Mind-Mapping therapy can be better understood. In the next section Mind-Mapping therapy will be viewed from the cognitive perspective in order to further elucidate this concept. The authors feel that a paradigm shift as to how we view our mental capacities, and those of our clients, is essential if we are to be more effective in our changing South Africa.

\section{Cognition.}

From the perspective of the information processing model, cognition involves a complex process with which an individual processes information for particular purposes, within certain mental structures and environmental constraints (Ylvisaker \& Szekeres, 1986).

Cognition is viewed by Feuerstein (1980) as mental acts that enable a person to think and therefore act intelligently. He adds another dimension to his definition by stating that well developed cognitive functions are the product of mediated learning experiences, i.e. the way in which stimuli emitted by the environment are transformed by a "mediating" agent, usually a parent, sibling or other caregiver. Through this process of mediation the cognitive structure of the child is affected. The child acquires behaviour patterns and learning sets, which in turn become important ingredients of his capacity to become modified through direct exposure to stimuli, hence cultural differences.
Since direct exposure to stimuli quantitatively constitutes the greatest source of the organism's exposure, the existence of sets of strategies and repertoires that permit the organism to efficiently use this exposure has considerable bearing upon cognitive development. Feuerstein's objective therefore, is "to change the cognitive structure of the retarded performer and to transform him into an autonomous independent thinker capable of initiating and elaborating ideas" (Hobbs in Feuerstein, 1980:viii).

This concept of modifiable cognition is what the first author's research aimed to investigate, thus Feuerstein's orientation is considered a further critical aspect of MMA theory (Leaf, 1990). Feuerstein (1980) is interested in how the organism learns and solves problems. In MMA therapy, the thought processes of the brain are being stimulated as information is being structured according to the way the brain functions. Thus, deficient thought processes and learning skills can be identified as the Mind-Maps are being constructed because the clients' thought processes are being evaluated. At the same time, correct patterns can be set up, which would be therapy.

Feuerstein's (1980) interest in the formal structure of thought as opposed to the content of the mind, has relevance in that, with the MMA which, aims at improving information processing, and cognitive processes, the formal structure of thought is also being improved.

To summarise, the MMA, like the Feuerstein approach, becomes a TEACH-TEST-TEACH paradigm and the therapist tries to promote the best possible learning and motivational conditions. The MMA programme progresses through simple to complex reasoning tasks. It is dynamic because the person's learning style is assessed in the act of learning which highlights the metacognitive strategies and styles that the person is using. The technique also encourages the individual to take charge thus ensuring carryover. This in turn, guides specific therapeutic intervention (Leaf, 1990). In the following section the MMA is further evaluated in terms of information processing.

\section{Information processing.}

Information processing refers to the analysis and synthesis of information in sequential steps (Neisser, 1976 in Ylvisaker, 1986). Information processing abilities can be divided into three stages, namely:-

- regulation of input

- encoding - storage - retrieval

- regulation of response (Ylvisaker \& Szekeres, 1986).

These stages become the goals of developing information processing skills. In information processing terms, humans are seen as highly sophisticated computers with elaborate programmes. Viewed from this perspective, the MMA can be seen as the operating system - somewhat comparable to MS DOS (the operating system of a computer) - of the brain allowing the programmes to work and, the more efficiently the operating system is being used, the greater the functioning of the programme.

\section{The techniques, forms and manner of the MMA.}

The term 'MMA rehabilitation' is used in a very broad sense to indicate the treatment of the cognitive communicative deficits identified in patients, namely: cognitively 
based communicative, behavioural and psychosocial deficits, as well as the narrowly defined deficits in component systems and processes (Ylvisaker \& Szekeres, 1986). Since the scope of the MMA is broad, an attempt is made to make it more manageable by distinguishing the general principles, forms and manner of the approach that guides treatment decisions.

The general principles provide the environment with therapy: the form of intervention provides the philosophy: and finally, the manner of intervention provides the way information in therapy is analysed. The Mind-Mapping technique described in this article was evolved into a specific treatment approach for $\mathrm{CHI}$ by the first author based on a literature review, and research. Thus the Mind-Mapping protocol is original research and is supported by a strong theoretical base (Leaf, 1990).

\section{The techniques of the MMA rehabilitation.}

The overall objective of the MMA is to achieve the effective functioning of patients in normal situations comparable to premorbid functioning.

The general techniques of the MMA are comparable to those of any treatment regime. There are a few specfic techniques, however, that are unique to the Mind-Mapping programme. These include techniques that are not uncommon in the realm of therapy such as relaxation, breathing and music. It is the combination of techniques that the researcher has put together as part of the standard procedure of Mind-mapping, that is unique.

The first of these techniques is relaxation. Relaxation means, "a realistic response to the environment with a minimum of needless energy expended" (Boone, 1977, p 151). Therefore, by using relaxation techniques, unnecessary tension is reduced. On a physiological level, relaxation results in an increase in secretion of the brain's natural opiates - endorphin and enkephalin - which are generated when one feels good or relaxed (Hand, 1986). This in turn relaxes the limbic system's negative potential, enabling the neurochemicals necessary for learning and remembering to be generated (Hand, 1986). Thus intellectual pursuit is allowed to progress more readily than when negative feelings prevail, and the patient is guided towards comfort management rather than stress management. According to Wolpe (1958) "As we inhibit the anxiety through relaxation, the stuttering problem recedes" (Boone, 1977).

The second technique of the MMA is the use of controlled breathing. Boone (1977) suggests the use of breathing techniques for voice patients with poor breathing patterns. Russell (1986), indicates that breathing exercises aid concentration by focusing attention on the energy interplay involved in breathing. According to Hand (1986), even though our brain is only approximately 3.5 pounds, it requires $25 \%$ of the body's oxygen intake to function optimally. For these reasons, breathing exercises are incorporated within the MMA approach.

The third technique incorporated into the MMA is the use of suggestion and visualisation. According to Van Riper (in Boone, 1977), suggestion and visualisation permeate all forms of therapy, including those practised in medicine. No patient seeks help without some expectation that his/her problem will be alleviated. Therefore, directly or indirectly, deliberately or unconsciously, some kind of suggestion and visualisation seems to be inherent in any therapeutic relationship. According to Lozanov \& Gateva (1989), using suggestion and visualisation enables people to make more effective use of their brain potential, because suggestion has a similar effect to relaxation physiologically (discussed under the principle of relaxation), and visualisation is essential to the process of activating memory (Russell, 1986).

Fourthly, the use of music - specifically Baroque music is advocated by the MMA to be used throughout therapy. Music is used due to the documented effect it has on the alpha and beta wave forms of the brain (Lozanov \& Gateva, 1989). Music activates neurons for purposes of relaxing muscle tension, changing pulse and producing long-range memories which are directly related to the number of neurons activated in the experience (Hand, 1986). Music relaxes major portions of the brain so that those which are active encounter little interference from other portions. Furthermore, there are different types of music for different types of activities, that is learning, relaxation and visualisation (Lozanov, \& Gateva, 1989). Baroque music specifically is important as this type of music is characterized as being generally relaxing, with a $4 / 4$ rhythm and 60 beats per minute. The relaxation is induced due to psychological entrainment of body rhythms (Hand, 1986).

Therefore, the techniques of relaxation, breathing, suggestion and visualisation, and music create the environment of the MMA procedure, the main objective being to create an optimal learning situation.

Finally, there are various other techniques derived from brain-behaviour relationships that are applied to the MMA intervention. These principles are adapted from Hand (1986) and Luria (1982), and include the following:

- Words are read aloud - this activates Broca's area, Wernicke's area, left hemisphere sensory and motor cortex and the angular gyrus.

- Words are read with emotion and inflection - this activates right hemisphere areas for prosodic functions, right motor and sensory cortex, and the limbic system.

- Pictorial images are developed and mind-maps are used throughout - thus the patient is being stimulated to think in a visual and organised way. This involves a major portion of the primary visual cortex, left and right motor sensory cortices, central and peripheral nervous system from the brain stem through the arms, hands and fingers.

- Key words on Mind-Maps allow for discrimination in the right visual cortex.

- Testing after review - this reinforces neuronal connections established during initial learning, leading to hypertrophy and/or branching of neuron dendrites, and making recall easier.

- The more vivid and active the impression of what is being learned, the stronger the memory trace. The spike of electrical activity in the brain increases markedly with novel, surprising or vivid stimuli. This activity signals the hippocampus and hypothalamus to produce increased levels of neurochemicals related to memory formation.

\section{The forms of the MMA.}

Rehabilitation efforts in general may take the form of facilitating spontaneous recovery, direct retraining of $\operatorname{cog}$ nitive components, retraining functional-integrative per- 
formance and compensation training. The Ylvisaker \& Szekeres (1986) approach indicates each of these forms of intervention as separate approaches in rehabilitation through which the patient in general progresses through, terminating in compensation training to overcome deficits not remediated directly.

The Mind-Mapping approach is more eclectic than the traditional therapy discussed above, and holistic in that the process of therapy is seen to work on components and functional-integrative performance concurrently. Therefore, there is no distinction between component and functional-integrative performance (Ylvisaker \& Szekeres, 1986). Furthermore, it is felt that the MMA encourages the brain to go beyond its capacity for spontaneous recovery, because patients are being taught a strategy that stimulates the whole brain resulting in increased efficiency (Leaf, 1990).

In conclusion - the MMA is not a form of compensation. In this approach, compensation is seen as for example, using logbooks to assist memory, or wearing glasses. MindMapping therapy is more, - it is a strategy to stimulate whole-brain learning.

The manner of MMA: Textlinguistics/Metaphors and the creation of the Mind-Map.

The analysis of textlinguistics as a vehicle for examining discourse beyond the sentence level has recently received attention by various groups of researchers (Liles, 1985).

Textlinguistics provides a logical ordered way of approaching the content (story, newspaper article, schoolwork) of therapy. Therefore, the story (metaphor) or macrostructure model of analysis provides the manner in which the MMA is done, that is, the manner in which the texts - oral and written - used in therapy are approached.

Textlinguistics also provides the organized steps of the thinking process that goes into the actual creation of the mind-map. Thus, the mind map becomes the visual representation of the cognitive process. The actual creation of the mind map stimulates both the left and right hemispheres, which increases the effectiveness of functioning. Therefore, a mutually beneficial cyclic process is set up (Buzan, 1991).

Based on the conceptual framework as discussed in 2.1. and the principles, forms and manner of the MMA in 2.2., a treatment model was designed by the first author. This is outlined in the form of a schematic layout in figure 1. In the treatment model, therapy is viewed as being divided into two aspects, namely the creation of an optimal learning environment, and then the actual process/steps of therapy. In the first, the brain is being prepared' or 'primed' to receive information and to function optimely by ensuring the correct physiological aspects (electrical and chemical and oxygen). The process takes the client through various steps which stimulate brain hemisphere synergy.

Discussion of the application of the MMA to a single case study of CHI.

A number of questions were addressed in a study by Leaf (1990) regarding the effectiveness of Mind-Mapping as a therapeutic intervention technique on a white female subject. The results revealed a statistically significant improvement in the academic ability of the CHI subject, which was proved to be directly attributable to the intervention program. There was also a statistically significant improvement of the subject in the indirectly treated cognitive-language skills and the untreated pragmatic skills, indicating generalization effects. It is this finding that supports the postulation that the MMA is a language and culture "free" technique. The results furthermore revealed increasingly competent post-treatment performance academically.

With specific regard to cognitive language abilities, it was deduced that Mind-Mapping improved the following skills in the subject (Leaf, 1990):

- to interpret alternative meanings in ambiguous statements by evaluating multiple meanings, features at the surface structure and features at the deep structure level

- to reason analytically, synthetically and logically

to interpret abstract concepts

- to improve retrieval so that it becomes an organised efficient memory search

- the processing of information

- to associate and identify relationships

- to select central concepts

- to identify, retrieve, sequence and produce semantic units - expression

- to identify, recall and retrieve appropriate grammatical structures - expression

to make judgements about concepts to attend and perceive.

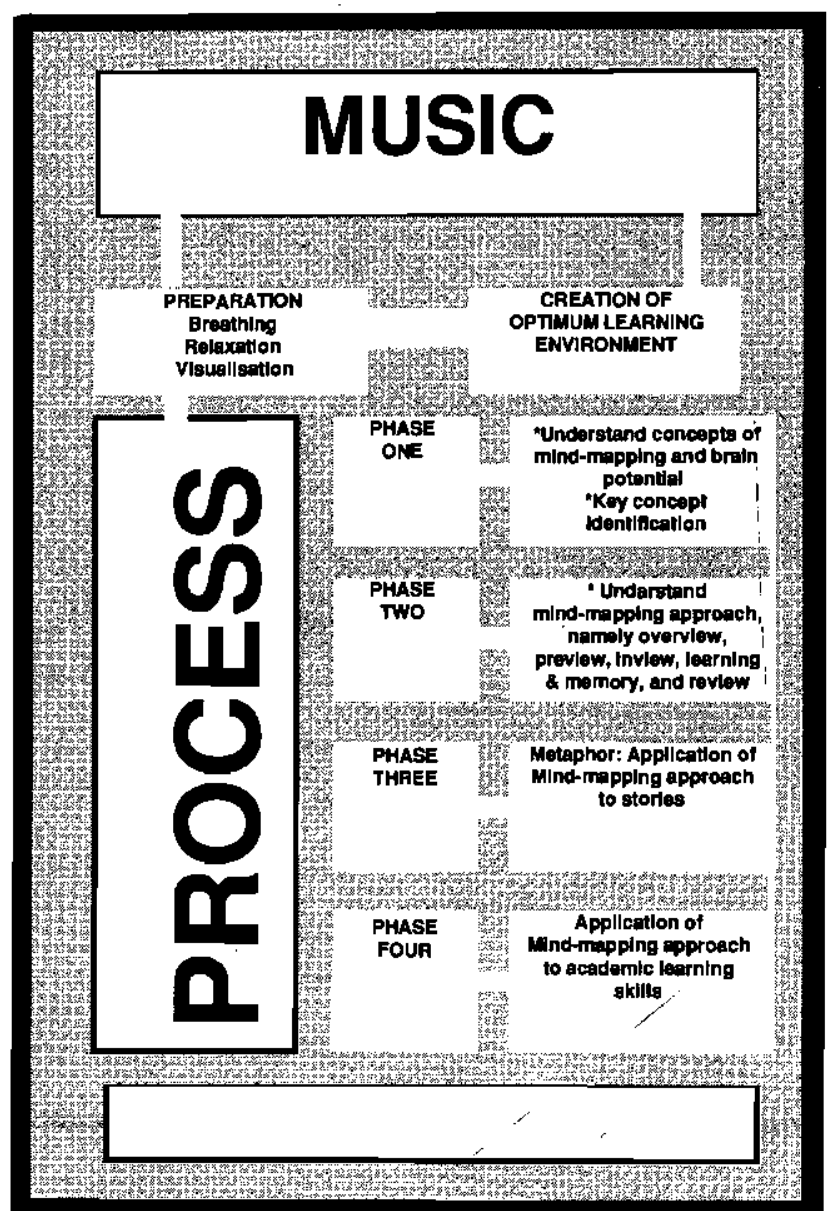

Figure 1. Schematic layout of mind-mapping intervention 
As the above receptive and expressive skills in the subject of the study (Leaf, 1990) were indirectly treated, the suggestion is that a certain amount of generalization took place. This implies that the cognitive dysfunction underlies the language function - further supporting the concept of the MMA being language and culture "free".

The improved psychosocial and pragmatic functioning of the subject - which were the untreated behaviours in the study (Leaf, 1990) - proved interesting as Prigatano (1986) had the same results in his intensive neuropsychological rehabilitation programme, but he had used professional neuropsychologists and clinical psychologists to help the patients as a separate part of their treatment. In the study conducted by Leaf (1990), the only therapy received by the subject was Mind-Mapping therapy conducted by a speech and language therapist, however, the same type of effects were obtained.

\section{CONCLUSION: APPLICATION OF THE MMA CROSS-CULTURALLY.}

In order to overcome the linguistic and cultural diversity that exists the world over, the study of normal and pathological communication must be couched in cultural terms. This would avoid the risk of making judgements about the communication of a given group from an inappropriate set of assumptions and norms (Taylor, 1986). Furthermore, cultural factors also determine the definition of what is pathological, i.e. the definition of the quality and normalcy of the environment (Taylor, 1986).

Likewise, "Treatment should take into account the preferred learning style of the client and the rules of social and communicative interaction as defined by the client's indigeneous cultural or linguistic group" (Taylor, 1986, $\mathrm{p} 7$ 7). Therefore all clinical encounters are cultural events requiring an ethnological approach. This implies a need for greater understanding of dialectical and language differences.

"However, the adoption of a dialectical perspective need not imply dramatically different clinical methods for every dialect" (Taylor, 1986). That is, the universal principles of therapy would not alter, but the material would. The learner is a product of his environment, thus, the material should be selected from his specific culture. In this way the learning process is concentrated on, and not the material.

Current diagnostic and treatment procedures emphasize middle class westernized values and are therefore not "culture free" (Bogatz in Taylor, 1986). The therapist working in a multi- cultural environment needs to expand the assessment and treatment process, to determine the client's learning potential as opposed to acquired knowledge (Taylor, 1986).

Mind-Mapping, as discussed, is a way of structuring information according to the way the brain functions, stimulating both hemispheres to function in harmony (Buzan, 1984). In this way, learning potential can be assessed and improved.

The MMA (Leaf, 1990) is the application of this concept into the realms of therapy by providing the clients with a more efficient "operating system" allowing them to use/access their potential more efficiently. It appeals directly to the multi-dimensional cognitive level and therefore reflects the cognitive processes underlying language. Mind-Mapping therapy incorporates a unique combina- tion of techniques that have been shown to stimulate a more efficient process of learning new information (Leaf, 1990). These include relaxation, breathing, and music which provide the environment of therapy (see Figure 1), which can be adapted to suit each individual.

By using the MMA (Leaf, 1990), the patient is not simply observing long lists of words or sentences, rather he is receiving each word in the context of the words that surround it. At the same time he is also giving the multiordinate nature of each word his own special interpretation as dictated by the structure of his personal information patterns - thus "culture free" - and, will be analysing, coding and criticising throughout the process.

In applying the MMA to a single CHI subject (Leaf, 1990), only multi-dimensional cognitive skills - as they pertained to academic abilities - were worked on directly, showing a statistically significant improvement. However, the indirectly treated receptive and expressive language skills, and untreated pragmatic and psychosocial functioning also improved significantly, allowing the subject to return to her premorbid level of functioning. This stresses the universality of the MMA, strengthening the possibility of the MMA being a culture and language "free" technique.

From this, one could postulate that by working via a common medium such as academic material, through using the MMA, one could circumvent the problem of language and culture bias. To this end, the MMA lends itself to being used within a consultative framework, such as suggested by Uys (1985), where a professional service is given indirectly through the use of a "consulting care person" (Uys \& Hay 1985, p 4). In other words, the MMA could be used within an empowerment framework, as the MMA is easy and effective to use in group situations. In this way large sectors of the population could be reached.

If a client is not schoolgoing, illiterate or has severely depressed functioning due to a neurogenic disorder, the MMA still has applicability due to its multi- dimensional and sensory nature. It is also a highly visual technique, lending itself to images and pictures instead of words, if this is required.

The first author has applied the technique on a clinical basis cross-culturally with Blacks, Coloureds, Indians, Chinese and Japanese. The results have been encouraging in terms of linguistic, cognitive and psychosocial functioning.

Various trends were also observed where certain of the MMA techniques were more appealing to certain cultures. For example, the Black students learned material more effectively using music by Steven Halpern \& Savary (adapted Baroque), whilst learning new activities. Although this music has no identifiable tune and does not have the orthodox tempo of 60 beats/minute, it has been shown to facilitate whole-brain learning (Halpern \& Savary, 1985). Clynes (in Halpern, 1985) indicates that there are specific forms of emotional expression - called "essentic forms" that act like keys in a lock and activate specific learning memory processes. Research suggests that essentic forms have innate meanings that transcend cultural learning and conditioning, and are therefore neurologically coded. It is possible that these essentic forms are more activated using this adapted type of music with black clients.

Critchley and Henderson (in Halpern \& Savary, 1985) found that this adapted Baroque music may be able to 
activate the flow of stored memory material across the corpus callosum, so that right and left hemispheres of the brain work in harmony rather than in conflict, resulting in improved functioning.

The Asian students, on the other hand, preferred the standard combinations of classical and Baroque music to the adapted music, learning more effectively with the former. Lozanov \& Gateva (1989), using Biofeedback, researched the effect of the standard classical and Baroque music, finding it to be a catalyst during the process of instruction with students.

The above clinical observations strengthen the premise that the technique of using music in Mind-Mapping therapy is a fundamental principle, and that the material - type of music - has a culture preference.

Futher corroborating the strength of the MMA as an alternative fundamental "culture-free" technique, is research conducted by Van Kraayenburg (1992). He applied a similar combination of techniques to that of Mind-Mapping therapy, within a scholastic programme to teach English to $\mathbf{5 4 0}$ Black South African schoolchildren in Sub B, Std 1 and Std 2. The result was that the programme was judged foremost by the Human Sciences Research Council, after two and a half years of evaluation against seven other suggested teaching programmes.

In conclusion, not only do we experience heterogeneity cross-culturally, but within each culture group there is diversity as well. Using more global techniques such as Mind-Mapping therapy, where the individual's perception, learning style and potential to learn and think are emphasized as opposed to a group or culture's language and thought patterns, bias can be circumvented. Thus, the aim should be to develop more global approaches to therapy focusing on creating richly varied culturally appropriate instructional environments. This should be done in a climate that fosters imagination, adventure and risk taking, all vital catalysts to learning. In this way we as speechlanguage therapists can try to deliver services to all individuals.

Einstein once said that imagination is more important than knowledge as knowledge is limited and imagination is not (Buzan, 1990). The authors believe that one of the ways to deal with the mammoth task of delivering services to all cultures in South Africa is to go beyond the realms of knowledge into that of imagination. Hopefully then, culture and language "free" techniques will be found.

\section{REFERENCES.}

Adamovich, B.B. (1986). Speciality Recognition in Neurogenic Speech, Language and Cognitive Disorders: Training needs of Speech-Language Pathologists regarding the Cognitive Rehabilitation of Closed Head Injured Persons. In R. Brookshire (Ed.), Clinical Aphasiology Conference Proceedings (AC). 16, 329-337. Minneapolis: BRK Publishers.
ASHA. (1991). REACH: A Model for the Service Delivery and Professional Development within Remote/Rural regions of the United States and U.S. Territories. Asha, 33, 6, 5-14.

Buzan, T. (1991). Use Both Sides of your brain. United States: First Plume Printing.

Boone, D.R. (1977). The Voice and Voice Therapy. New Jersey: Prentice-Hall.

Feuerstein, R. (1980). Instrumental Enrichment: An Intervention Programme for Cognitive Modifiability Baltimore: University Park Press.

Hagen, C. (1984). Language Disorders in Head Trauma. In A.L. Holland (Ed.), Language Disorders in Adults: Recent Advances.

San Diego: College-Hill Press.

Halpern, S and Savary, L. (1985). Sound Health: The Music and Sounds That Make us Whole. San Francisco: Harper \& Row Publishers.

Hand, J.D. (1986). The Brain and Accelerative Learning. Per Linguam, 2, 2, 2- 14.

Hay, I.S. \& Uys, I.C. (1985) Taalverskeidenheid en Taalpatalogie: Universiteit van Pretoria.

Leaf, C.M. (1990). Mind-Mapping: A Therapeutic Technique for Closed Head Injury. Unpublished Master's Dissertation, University of Pretoria.

Liles, B. (1985). Production and Comprehension of Narrative Discourse in Normal and Language Disordered Children.Journal of Communication Disorders, 18, 409-427.

Lozanov, G. \& Gateva, E. (1989). The Foreign Language Teacher's Suggestopedic Manual. Switzerland: Gordon and Breach Science Publishers.

Luria, A.R. (1982). Language and Cognition. Washington: Winston \& Sons.

Ornstein, R.E. (1975). The Psychology of Consciousness. New York: Penguin Books.

Penn, C. and Cleary, J. (1988). Compensatory Strategies in the Language of Closed Head Injured Patients. Brain Injury, 2, 1, 3-17.

Powell, G.E. (1981). Brain Function Therapy. Great Britain: Gower.

Prigatano, G.P. (1986). Neuropsychological Rehabilitation after Brain Injury. Baltimore: John Hopkins University Press.

Rosenzweig, M.R. and Bennet, E.L. (1976). Neuronal Mechanisms of Learning and Memory. Cambridge: MIT Press.

Russell, P. (1986). The Brain Book. London: Routledge \& Kegen Paul.

Scott, B.S. (1976). The effect of elevated potassium on the time course of neuron survival in cultures of dissociated dorsal root ganglia. Journal of Cellular Physiology, 91, 305-316.

Sperry, R.W. (1982). Some Effects of Disconnecting the Cerebral Hemispheres. Science, 217, 1223-1226.

Taylor, O.L. (1986). Treatment of Communication Disorders in Culturally and Linguistically Diverse Populations (Ed.). California: College-Hill Press.

Van Kraayenberg, F. (1992). Lecture Series: Creative Accelerative Learning Methods: Lead the Field, Johannesburg.

Ylvisaker, M.A. \& Szekeres, S.F. (1986). Management of the Patient with Closed Head Injury. In Brookshire, R. (Ed.), Clinical Aphasiology Conference Proceedings. Minneapolis: BRK Publishers.

Zaidel, E. (1985). Roger Sperry: An Appreciation. In Ben'son, D.F. \& Zaidel, E. (Eds.), The Dual Brain. New York: The Guilford Press. 